\title{
The risk of suicide after deliberate self harm was significant and persistent over the long term
}

Hawton K, Zahl D, Weatherall R. Suicide following deliberate self-harm: long-term follow-up of patients who presented to a general hospital. Br J Psychiatry 2003;182:537-42.

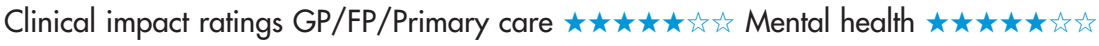

In patients who presented to a general hospital after deliberate self harm, what is the short term and long term risk of suicide?

\section{METHODS}

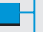

Design: Inception cohort with median follow up of 10.8 years (follow up range $1 \mathrm{~d}$ to $23 \mathrm{y}$ ).

Setting: Accident and emergency departments in general hospitals in Oxford, UK

Patients: 11583 patients ( $47 \%$ aged $10-24 \mathrm{y}$ ) who presented to a general hospital after deliberate self harm during the 20 year period between 1978 and $1997.10353(89 \%)$ patients used self poisoning as the method of self harm.

Assessment of prognostic factors: A register was used to collect data on all deliberate self harm presentations to the general hospital in Oxford (including non-admitted patients and those admitted to hospital). Deliberate self harm included intentional self poisoning or self injury, irrespective of motivation.

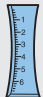

Outcomes: Suicide or probable suicide (probable suicide was defined as an "undetermined cause" or "accidental poisoning" coroner's verdict on death certificate). These data were obtained from the Office for National Statistics for England and Wales and equivalent mortality registers in Northern Ireland and Scotland.

\section{MAIN RESULTS}

During follow up, $300(2.6 \%)$ patients died by suicide or probable suicide. Of these, a clear suicide verdict was recorded for $177(59 \%)$

Risk of suicide after deliberate self harm*

\begin{tabular}{|c|c|c|c|}
\hline $\begin{array}{l}\text { Time since first } \\
\text { presentation } \\
\text { for deliberate } \\
\text { self harm }\end{array}$ & $\begin{array}{l}\text { Overall risk } \\
(95 \% \mathrm{Cl}) \\
(\mathrm{n}=11583)\end{array}$ & $\begin{array}{l}\text { Risk in men } \\
(95 \% \mathrm{Cl}) \\
(\mathrm{n}=4622)\end{array}$ & $\begin{array}{l}\text { Risk in women } \\
(95 \% \mathrm{Cl}) \\
(\mathrm{n}=6961)\end{array}$ \\
\hline & & & \\
\hline 5 years & 9) & 1) & 1.3) \\
\hline 10 years & $2.4 \%(2.1$ to 2.7$)$ & $4.0 \%$ (3.5 to 4.7$)$ & $1.4 \%(1.1$ to 1.7$)$ \\
\hline 15 years & $3.0 \%(2.6$ to 3.4$)$ & $4.8 \%(4.1$ to 5.6$)$ & $1.8 \%$ (1.5 to 2.2$)$ \\
\hline
\end{tabular}

*Risks are based on Kaplan Meier estimates.

For correspondence: Professor K Hawton, Warneford Hospital, Oxford, UK keith.hawton@psych.ox.ac.uk

Source of funding: National Health Service Executive for England. patients, an undetermined cause verdict for $82(27 \%)$ patients, and an accidental poisoning verdict for 41 (14\%) patients. $113(38 \%)$ patients used poisoning as the method of suicide, and $64(21 \%)$ patients used hanging, strangulation, or suffocation as the method of suicide. The table shows data on the risk of suicide after deliberate self harm. The risk of suicide was greater for men than for women (hazard ratio $2.8,95 \%$ CI 2.2 to 3.6 ). In both men and women, the risk of suicide increased with increasing age at the time of the initial self harm episode. No major change in risk of suicide during the 20 year study period was seen.

\section{CONCLUSION}

Among patients who presented to a general hospital after deliberate self harm, the risk of subsequent suicide was significant, persisted over the long term, and varied between sex and age groups.

\section{Commentary}

7 his important study by Hawton et al is the latest in a number that identifies deliberate self harm (or parasuicide) as a harbinger of completed suicide. The study sample is large, the methodology rigorous, and the conclusions unequivocal. In the 15 years after a self harm episode, a much greater risk of suicide continues to exist over the whole time period. However, the risk is greatest in the first year after the self harm event. Other data suggest that this risk extends beyond 20 years, ${ }^{1}$ thus the risk may be lifelong. As one of the main aims of public mental health is to reduce suicide, preventive potential exists here.

We are also not dealing here with a statistical risk of no clinica relevance: a risk 66 times greater than that in the normal population is substantial. The particularly relevant data for psychiatric services is the much greater risk in the older population (ie, those aged $>55 \mathrm{y}$ ). This is not a group that has high rates of self harm, and a case can be made for targeting treatment resources in older people. However, we do not yet have brief interventions of undoubted efficacy for the large group at risk ${ }^{2}$ although we are getting closer; ${ }^{3}$ the main problem is that so many who harm themselves do not come back for treatment even if it is offered. Peter Tyrer, MD, FRCP, FRCPsych, FFPHM Department of Psychological Medicine, Imperial College
London, UK

1 Jenkins GR, Hale R, Papanastassiou M, et al. Suicide rate 22 years after parasuicide: cohort study. BMJ 2002;325:1155.

2 Bennewith O, Stocks N, Gunnell D, et al. General practice based intervention to prevent repeat episodes of deliberate self harm: cluster randomised controlled trial. BMU 2002;324:1254-7.

3 Tyrer P, Thompson S, Schmidt U, et al. Randomized controlled trial of brief cognitive behaviour therapy versus treatment as usual in recurrent deliberate self-harm: the POPMACT study. Psychol Med 2003;33:969-76. 